\title{
A critical age: can we reliably measure frailty in critical care?
}

Richard J. Pugh ${ }^{1 *}$, Chris M. Thorpe ${ }^{2}$ and Christian P. Subbe ${ }^{3,4}$

Keywords: Frailty assessment, Frailty, Clinical Frailty Scale, Reliability, Critical care, Critically ill

As populations age, the proportion of older patients admitted to critical care units has risen in a number of nations [1]. Age remains an independent predictor of poorer short- and long- term outcomes following critical care admission [1], but the distinction between "physiological" and "chronological" age has long been apparent to critical care clinicians. For the critically ill, assessment of frailty ("a condition characterised by loss of biological reserve and vulnerability to poor resolution of homeostasis following a stressor event" [2]) offers the potential both to inform discussions when escalation of care is being considered, and to identify those who may need a higher level of support in their recovery from critical illness. Although several reports regarding the predictive validity of frailty assessment tools in the critically ill have been published recently [3], study of the reliability of such assessments is virtually absent from the critical care literature.

We therefore undertook a prospective study of consecutive patients admitted to a single UK critical care unit. Frailty was assessed with regards to condition 2 weeks prior to hospital admission using the Clinical Frailty Scale (CFS) [4]. Assessments were performed independently by a medical student and a critical care doctor following interviews with the patient and/or family. Inter-rater reliability was assessed using linearweighted kappa.

Assessments of frailty were made for 30 patients (median age 70.5 years, 60\% male, median Acute Physiology and Chronic Health Evaluation (APACHE) II score 16, median CFS 3 (interquartile range (IQR) 2-5). The frequency distribution of CFS scores is presented in Fig. 1. Linear weighted kappa was 0.64 (95\% confidence intervals 0.40 to $0.87 ; p<0.0001$ ), suggesting a good level of agreement.

The major limitations of our preliminary study are that the study population was small, it was single-centre, and that patients with higher CFS scores were relatively under-represented (in line with previous reports [3]). There are potential difficulties in assessing frailty in the context of acute illness [5]; however, in spite of a reliance on proxies (e.g. family members) to make the assessment we have found that with appropriate training the application of frailty assessment tools in the critically ill can be reliable. Given the potential utility of frailty assessment in clinical practice, administration and research, there is a need to evaluate the clinimetric properties of frailty assessment tools in the critically ill with larger, multi-centred studies.

\footnotetext{
*Correspondence: richard.pugh@wales.nhs.uk

1 Department of Anaesthetics, Glan Clwyd Hospital, Bodelwyddan,

Denbighshire, Wales LL18 5UJ, UK

Full list of author information is available at the end of the article
} 


\section{Clinical Frailty Scale}

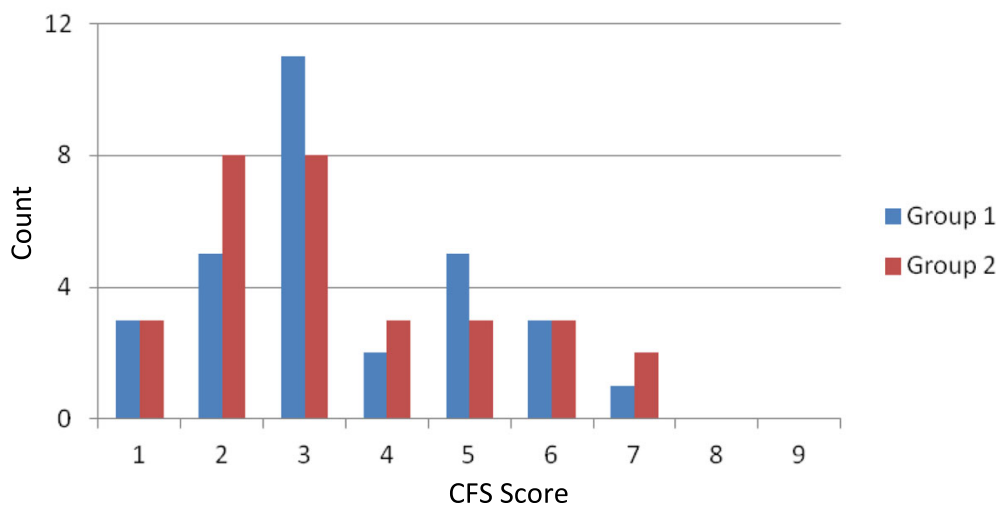

Fig. 1 Frequency distribution of Clinical Frailty Scale (CFS) scores. Frequency distribution of assessments of CFS (30 patients, each undergoing an assessment by Group 1 (Medical Students) and an assessment by Group 2 (Critical Care doctors))

\section{Abbreviation}

CFS: Clinical Frailty Scale

\section{Acknowledgements}

We are grateful to Elen Rowlands and Mark Shipway for their role in data collection, and to Rhiannon Whitaker for statistical support.

\section{Funding}

The study was unfunded.

\section{Availability of data and materials}

The datasets used and/or analysed during the current study are available from the corresponding author on reasonable request.

\section{Authors' contributions}

CPS, CMT, and RJP designed the study, oversaw data collection, and co-wrote the manuscript. All authors read and approved the final manuscript.

\section{Competing interests}

The authors declare that they have no competing interests.

\section{Consent for publication}

Consent for publication was not required.

\section{Ethics approval and consent to participate}

This study received institutional approval from the Audit Department at Ysbyty Gwynedd, Betsi Cadwaladr University Health Board as preliminary work in a quality improvement project. As such, ethical approval and consent were not required.

\section{Publisher's Note}

Springer Nature remains neutral with regard to jurisdictional claims in published maps and institutional affiliations.

\section{Author details}

${ }^{1}$ Department of Anaesthetics, Glan Clwyd Hospital, Bodelwyddan, Denbighshire, Wales LL18 5UJ, UK. ²Department of Anaesthetics, Ysbyty Gwynedd, Bangor, Gwynedd, Wales LL57 2PW, UK. ${ }^{3}$ Acute, Respiratory and Intensive Care Medicine, Ysbyty Gwynedd, Bangor, Gwynedd, Wales LL57 2PW, UK. ${ }^{4}$ School of Medical Sciences, Bangor University, Bangor, Gwynedd, Wales LL57 2DG, UK.
Published online: 31 May 2017

\section{References}

1. Bagshaw SM, Webb SA, Delaney A, George C, Pilcher D, Hart GK, Bellomo R. Very old patients admitted to intensive care in Australia and New Zealand: a multi-centre cohort analysis. Crit Care. 2009;13(2):R45

2. Clegg A, Young J, lliffe S, Rikkert MO, Rockwood K. Frailty in elderly people. Lancet. 2013;381(9868):752-62.

3. Bagshaw SM, Stelfox HT, McDermid RC, Rolfson DB, Tsuyuki RT, Baig N, Artiuch B, Ibrahim Q, Stollery DE, Rokosh E, et al. Association between frailty and short- and long-term outcomes among critically ill patients: a multicentre prospective cohort study. CMAJ. 2014;186(2):E95-102.

4. Rockwood K, Song X, MacKnight C, Bergman H, Hogan DB, McDowell I, Mitnitski A. A global clinical measure of fitness and frailty in elderly people. CMAJ. 2005;173(5):489-95.

5. NICE. Multimorbidity: clinical assessment and management. In: Multimorbidity: assessment, prioritisation and management of care for people with commonly occurring multimorbidity. London: National Institute for Health and Care Excellence; 2016 